\title{
The Problems of Academic Misconducts and Approach to Resolve
}

\author{
Shu-hui WANG \\ Academy of Armored Force Engineering \\ Department of Scientific Research \\ Beijing, China, 100072 \\ ilysmwsh@163.com \\ Sheng-feng WANG \\ Academy of Armored Force Engineering \\ Department of Scientific Research \\ Beijing, China, 100072 \\ xuebaozjb@163.com
}

\author{
Yan-ping NIU \\ Academy of Armored Force Engineering \\ Department of Scientific Research \\ Beijing, China, 100072 \\ xuebaozjb@163.com \\ Cai-juan SHANG \\ Academy of Armored Force Engineering \\ Department of Scientific Research \\ Beijing, China, 100072 \\ yanpingniu@163.com
}

\author{
Fei-fei SHANG \\ Academy of Armored Force Engineering \\ Department of Scientific Research \\ Beijing, China, 100072 \\ xuebaozjb@163.com
}

\begin{abstract}
At present, academic misconducts prevail in the academic circle, which exert a serious negative effect on the society. On the basis of a large number of literature, the causes for academic misconducts have been discussed in the paper. It is mainly includes researchers' weak moral awareness, academic evaluation system and the supervision and punishment mechanism. To precaution against academic misconducts, the problem of unreasonable exiting academic evaluation system should be improved. At the same time, an effective preventives mechanism for scientific periodicals need to been established. The purpose of paper is to root out propagation of academic misconducts, create a pure academic atmosphere, and practically improve the academic level of scientific journals.
\end{abstract}

Keywords-Academic misconduct; scientific journal; preventive strategy; responsibility; editing ability

\section{INTRODUCTION}

In recent years, abundant information can be acquired more and more easily with rapid high-tech development and popularity of Internet. This brings many conveniences to people in daily life, but more academic misconducts are propagated. A wide variety of paper databases such as China National Knowledge Infrastructure (CNKI) are supposed to be the resources for mutual study and reference, but reversely, they become the original data banks of paper plagiarism, so that a paper can be made only by "Cut + Paste". These misconducts undermine and degrade social morality seriously.

\section{PRESENTATION OF ACADEMIC MISCONDUCTS}

Internationally, the academic misconducts are mainly presented as data fabricating, data tampering and plagiarism. A wide range of academic misconducts occur in China. Besides data fabricating, data tampering and plagiarism, they also include duplicate submission, embezzling academic achievements, improper signature, and counterfeiting academic record [1-3].

\section{CAUSES FOR ACADEMIC MISCONDUCTS}

The academic misconduct is not a fresh topic, and it occurred in the ancient and modern times, as well as at home and abroad. There are many causes for occurrence of the misconduct. From China's present stage, the academic misconducts are originated from researchers' weak moral awareness of honesty and morality, unreasonable exiting academic evaluation system and lack of effective supervision and punishment mechanism [4-6]

\section{A. Researchers' weak moral awareness of honesty and morality}

Honesty is the essence of long-standing success in society, and the pursuit of truth is the basic rule of scientific research. As respected science researchers, they should strive to develop their own characters of observing academic norms and strict self discipline, which are the most basic academic morals [7]. 
As China is standing at the social transition stage, people's moral and value outlooks change greatly. The researchers' working goal was to seek the truth 30 ago, while nowadays most of researchers' goal tends to utilitarian after 30 years, where scientific research fund is not a thing serving researches any more, but becomes an index to measure their achievements. Some of researchers take the academic research as a means to fish for fame and credit and pursue economic benefits, and put their excessive energy in professional title appraisal, post promotion and application for task project. Being dominated by the philosophy of quick success and instant benefits, they don't work at academic researches any more by a rigorous attitude, but pursue quantity of publications one-sidedly and bucking for more benefits by any kind of means[1]. Without doubt, the researcher, as a social man, is certainly affected by social overall situations. As a result, some researchers couldn't hold out moral bottom line so that they did the misconducts of violating academic integrity in the general background of extremely expanding personal desires and prevailing of social utility.

\section{B. Unreasonable exiting academic evaluation system}

Currently, China's academic evaluation system is characterized by excessive quantization. Many colleges and research institutions take the number of publications (papers and monographs) as major indicators for performance appraisal of degree awarding, professional title appraisal and project conclusion [8]. The teachers in universities and colleges are often charged with arduous teaching tasks, and often on lesson preparing and giving, and students coaching, so that they have no time and energy to write papers and monographs. Besides that, they are faced with the pressure of annual evaluation and professional title appraisal. As is well-known, the scientific exploration is a long-term and arduous task, and the success can be made in any of new scientific results or theories only by numerous failures and explorations. So it needs a long process for the researchers to get down and do researches in a down-toearth way, and it is impractical to achieve a breakthrough within a short term. However, the current academic evaluation system requires the evaluation once a year or even half a year. Thus, vast teachers and researchers have to spend their precious time and energy to satisfy the requirements of appraisal indexes. As a result, the academic misconducts such as production of junk papers as well as falsification and paper deal prevail.

\section{Lack of effective supervision and punishment mechanism}

At present, China has not established a special regulatory and supervisory body for academic misconducts, and quite a number of academic rule-breaking events were handled covertly within relevant units. Even so, it is still lack of transparency and openness, and these practices may cover up academic misconducts to a certain extent. Moreover, there is no perfect legislation in control of academic misconducts [9]. Although such laws as Patent Law, Copyright Law, Trademark Law and other enforcement regulations have been enacted at a national level in intellectual property protection (IPR), these existing legal provisions fail to involve in all academic misconducts, so that some illegal behaviors are free out of the lawful divisions in the academic circle, and the violators didn't receive a deserved punishment. Conventionally, China's constraints of academic specifications go by researchers' moral self-discipline for the most part. With continuous exposures of domestic academic rule breaking events, the researchers' honesty has been suspected extremely, and it is realized gradually that the control of academic misconducts is impossible only by virtue of moral education. In recent years, relevant government departments and scientific research institutions also rolled out some measures and policies to punish the academic misconducts. But their regulatory framework and inner instructive documents exerted a general effect due to lack of lawful deterrence as well as light penalty and small range of enforcement. As a matter of fact, establishing the complaint mechanism for academic misconducts, improving legislation in academic integrity and enhancing supervision and penalty are the essential guarantees for control of academic misconducts.

\section{PRECAUTIONS AGAINST ACADEMIC MISCONDUCTS}

The scientific journal is an important platform exhibiting scientific achievements, carrying an important task to propagate latest views and approaches in academic researches. At the same time, it is also a forward position contacting academic misconducts [10]. So it undertakes an obligatory responsibility to prevent and put an end to academic misconducts.

\section{A. The editors should enhance their awareness of professional ethics and responsibility and improve their business ability; they should live up to the followings:}

1) Emphasis on their ideological and moral cultivation: They should set up the right outlook

On value and life, really love the editing cause, and cultivate themselves to have the selfless dedication that is indifferent to fame and fortune but ready to help others. It is believed that an editor of good character has genuinely a sense of resistance against social ugly phenomena from the bottom of their heart; in an attitude responsible for readers and periodicals, he can consciously reject all kinds of bad faith behaviors in academy to safeguard the solemnity of science.

\section{2) Emphasis on their ideological and moral cultivation}

They should set up the right outlook on value and life, really love the editing cause, and cultivate themselves to have the selfless dedication that is indifferent to fame and fortune but ready to help others. It is believed that an editor of good character has genuinely a sense of resistance against social ugly phenomena from the bottom of their heart; in an attitude responsible for readers and periodicals, he can consciously reject all kinds of bad faith behaviors in academy to safeguard the solemnity of science.

\section{3) Consciousness of responsibility}

As the gate-keeper of academic publishing, an editor should dare to resist academic corruptions, and require a sound paper quality control; should bravely adhere to principles to really accept best manuscripts on a selective basis, and reject acceptance of manuscripts by connection and relation; resolutely shut out contributions which are made from a patchwork quit, at a low academic level, or in a plagiarizing 
way [1]. If every editor can do by that way, it is sure that those academic counterfeiters dare not intrigue and act ruthlessly, and our academic circle will be certainly healthy and pure a lot.

\section{4) Improvement of editing ability}

With expansion of periodical influence, the manuscripts are richer for scientific periodicals, but they are made at a different level. So the editors are required to have higher academic evaluation ability to examine them. They should not deliver the manuscripts completely to experts for review, and the first thing for editors is to have a strictly preliminary examination. An outstanding editor should master the systematic specialized knowledge, academic trends and latest research achievements, know well the principles of method of academic evaluation, and accumulate the experience in the evaluation. These are of great help to identify academic misconducts of a paper [2]. Only by virtue of his stronger specialized quality, an editor can conduct correct judgment on academic level of the contributions, so as to put an end to the manuscripts with academic misconducts. Hence, an editor should actively do some specialized and academic researches and improve his own knowledge level at the same time of completing his own work.

\section{B. Effective preventive mechanism for scientific periodicals}

1) The editorial department should establish manuscript management system, and create the authors' credit guarantee and punishment mechanisms.

Firstly, the person in charge of the editorial department should sign a letter of commitment with the author according to requirements, and the author is required to guarantee his or her manuscript is an initial contribution without such academic misconducts as duplicate publication, plagiarism and infringement to others' research achievements; if any conduct of violating relevant provisions is found, the author and his or her units should bear all the consequences [3]. Secondly, the author who has academic misconducts should be punished severely without any tolerance. He or she should be treated by two cases: (1) The authors who are not informed or don't cause bad influences such as improper signature should be educated and alerted, and requested to correct his or her misconducts immediately; (2) Those who have violate knowingly relevant provisions and have offence of vicious or serious natures such as plagiarism or duplicate publication, should be notified by letter to be severely reprimanded; in terms of his bad influence degree, the editorial department should not accept the offender's contribution any more or pipe him or her off, and his or her manuscript should not be accepted forever.

\section{2) Application of CNKI manuscript detecting system}

Taking a comparing resource of the China Science Literature Network Publish General Storeroom, the CNKI academic misconduct detecting system can swiftly and accurately detect academic misconducts such as plagiarism, multiple contributions or improper signature, and directly check out the source of the plagiarized literature for full test comparison. This brings great conveniences to editors for reviews, and eradication of academic dishonorable behaviors to the maximum. Of course, the editors should not take the data from the system detecting report simply and mechanically as the only standard to evaluate a paper, and they are required to conduct overall analysis on content, core parts, and related literature of a manuscript, and make correct and comprehensive judgment in the end.

3) Improving work efficiency and shortening the period of manuscript review

In order to ensure the periodical quality, all manuscripts should go through several procedures such as academic misconduct detecting, preliminary review, and external review, final review, editing and revising, and proofreading. Editors should choose carefully the manuscripts in the preliminary review, work at them with great care before publishing, and also carry out the Three-Review System strictly which needs quite workload in this process. Thus, it is a longer period from the author's contribution to official publishing. However, the author has no idea of all this, and always complains the lag time of publishing to his or her paper or even thinks to receive no response too long, which is an objective cause that leads to author's multiple contributions with one manuscript. So the editorial department should work out strict time nodes for manuscript review, speed up handling of manuscripts, and timely urge experts for external review to shorten the publishing period. Moreover, they should often keep a touch with the author, so that the author can know review progress. By this way, such academic misconducts as duplication submissions may be avoided effectively.

The academic misconducts occur generally in subjective and objective reasons. The joint efforts of all walks of life should be made to contain the propagation and spread of academic misconducts, not only strengthening academic integrity education and working out preventive punishment. By this, the academic misconducts can be put an end from the source to purify academic atmosphere.

\section{CONCLUSION}

Academic misconducts prevail in the academic circle, which exert a serious negative effect on the society.

The reasons for academic misconducts prevail are mainly include researchers' weak moral awareness, academic evaluation system and the supervision and punishment mechanism.

To precaution against academic misconducts, the problem of unreasonable exiting academic evaluation system should be improved. At the same time, an effective preventives mechanism for scientific periodicals need be established. 


\section{REFERENCES}

[1] Brian Winrow. Do perceptions of the utility of ethics affect academic cheating.Journal of Accounting Education, Volume 37, December 2016, Pages 1-12.

[2] Dora Nazaré Marques, António Filipe Macedo.Perceptions of acceptable conducts by university students.Journal of Optometry, Volume 9, Issue 3 , July-September 2016, Pages 166-174.

[3] Elizabeth Fisher, Alexander J. McLeod, Arline Savage,et.al. Ghostwriters in the cloud.Journal of Accounting Education, Volume 34, March 2016, Pages 59-71.

[4] Eun-Jun Park, Seungmi Park, In-Sun Jang.Clinical Misconduct Among South Korean Nursing Students. Nurse Education Today, Volume 34, Issue 12, December 2014, Pages 1467-1473.

[5] Hadijah Iberahim, Norashikin Hussein, Nusrah Samat,et.al. Academic Dishonesty: Why Business Students Participate in these
Practices.Procedia - Social and Behavioral Sciences, Volume 90, 10 October 2013, Pages 152-156.

[6] Theresa Mitchell, Jude Carroll.Academic and research misconduct in the PhD: Issues for students and supervisors. Nurse Education Today, Volume 28, Issue 2, February 2008, Pages 218-226.

[7] Ben R. Martin. Keeping plagiarism at bay-A salutary tale.Research Policy, Volume 36, Issue 7, September 2007, Pages 905-911.

[8] Mary G. Harper. High tech cheating.Nurse Education Today, Volume 26, Issue 8, December 2006, Pages 672-679.

[9] Noorhidayah Abu Talib, Sarina Othman, Khamsi Che Abdul Hamid,et.al Alternative Dimension towards Integrity: A Perception of University Researchers. Procedia - Social and Behavioral Sciences, Volume 90, 10 October 2013, Pages 940-948.

[10] Patricia A. Prescott. Academic misconduct: Considerations for educational administrators. Journal of Professional Nursing, Volume 5, Issue 5, September-October 1989, Pages 283-287. 